Open Access Full Text Article

\title{
Apatinib in Patients with Relapsed or Refractory Diffuse Large B Cell Lymphoma: A Phase II, Open-Label, Single-Arm, Prospective Study
}

This article was published in the following Dove Press journal: Drug Design, Development and Therapy

\section{Xinran $\mathrm{Ma} \mathbb{D}^{*}$ \\ Ling Li* \\ Lei Zhang \\ Xiaorui Fu \\ Xin Li \\ Xinhua Wang \\ Jingjing Wu \\ Zhenchang Sun \\ Xudong Zhang \\ Xiaoyan Feng \\ Yu Chang \\ Zhiyuan Zhou \\ Feifei Nan \\ Jieming Zhang \\ Zhaoming Li $\mathbb{D}$ \\ Mingzhi Zhang (1D}

Department of Oncology, The First Affiliated Hospital of Zhengzhou University, Lymphoma Diagnosis and Treatment Center of Henan Province, Zhengzhou, Henan, People's Republic of China

*These authors contributed equally to this work
Correspondence: Mingzhi Zhang Department of Oncology, The First Affiliated Hospital of Zhengzhou University, Lymphoma Diagnosis and Treatment Centre of Henan Province, Zhengzhou 450002, Henan, People's

Republic of China

Tel +86-13838565629

Email mingzhi_zhangI@I63.com
Purpose: Treatment options for relapsed or refractory diffuse large B-cell lymphoma (RR DLBCL) represent an unmet medical need. Apatinib is a new oral tyrosine kinase inhibitor mainly targeting vascular endothelial growth factor receptor-2 (VEGFR-2) to inhibit tumour angiogenesis. In the present study, we evaluated the efficacy and safety of apatinib for patients with RR DLBCL.

Patients and Methods: In this phase II, open-label, single-arm, prospective study, we enrolled patients aged 14-70 years with treatment failure of at least two chemotherapeutic regimens using Simon's two-stage design. All patients were administered apatinib at an initial dose of $500 \mathrm{mg}$ on a 4-week cycle at home and visited the outpatient clinic every two cycles to evaluate efficacy and to record adverse events. We considered objective response rate (ORR) as the primary end point, and progression-free survival (PFS), and overall survival (OS) plus duration of response (DoR) as the secondary end point. (This trial was registered at ClinicalTrials.gov, identifier: NCT03376958.).

Results: From January 2017 to February 2019, we screened 35 patients and enrolled 32 eligible patients. At the cutoff point (April 2019), we noted 2 (6.3\%) complete responses, 12 (37.5\%) partial responses, and 9 (28.1\%) stable diseases, attributing to an ORR of $43.8 \%$ and a disease control rate of $71.9 \%$. The median PFS and OS were 6.9 (95\% confidence interval [CI], 5.8-7.9) and 7.9 months (95\% CI, 7.0-8.7), respectively. The median DoR was 5.0 months (95\% CI, 3.5-6.5) for patients who achieved PR. The most common grade 3-4 adverse events (AE) were hypertension (12.6\%), hand-foot syndrome (9.4\%), and leucopenia $(6.3 \%)$. No apatinib-related deaths were noted.

Conclusion: Home administration of apatinib shows promising efficacy and manageable AEs in patients with RR DLBCL.

Keywords: apatinib, relapsed or refractory diffuse large B-cell lymphoma, VEGFR-2, efficacy, safety

\section{Introduction}

Diffuse large B-cell lymphoma (DLBCL) is the most common lymphoid system malignancy in adults, accounting for $30-40 \%$ of all non-Hodgkin lymphomas (NHLs). ${ }^{1}$ For patients with newly diagnosed DLBCL, rituximab combined with cyclophosphamide, doxorubicin, vincristine, and prednisone (R-CHOP)-like regimen is the current standard, and local radiotherapy is recommended for those who meet the conditions. After initial treatment, approximately one-third of all patients manifest relapse or refractory disease. ${ }^{2}$ For this group of patients, second-line 
regimens, such as ifosfamide, carboplatin, and etoposide (ICE); dexamethasone, cytarabine, and cisplatin (DHAP); and gemcitabine, dexamethasone, and cisplatin (GDP) with or without rituximab are often chosen as salvage treatment; however, the long-term survival rate is $<10 \%$, and most patients die within 2 years. ${ }^{3}$ For eligible patients, we aim for autologous stem cell transplantation (ASCT), but many patients are ineligible. However, ASCT has limitations, such as a recurrence rate of $41.2 \%$ reported by a retrospective study. ${ }^{4}$ Clinical trials are recommended for patients with relapsed or refractory DLBCL (RR DLBCL). ${ }^{5}$

Angiogenesis plays a crucial part in the development and progression of a series of malignancies, including lymphoma. ${ }^{6,7}$ Apatinib is a new oral kinase inhibitor mainly targeting vascular endothelial growth factor receptor-2 (VEGFR-2) to inhibit tumour angiogenesis and has shown encouraging anti-tumour effects in multiple solid tumours, including gastric cancer, ovarian cancer, non-small-cell lung cancer, breast cancer, osteosarcoma, etc. ${ }^{8-12}$ To date, clinical evidence of apatinib as a potential treatment choice for RR DLBCL remains scarce. Laboratory work shows that apatinib inhibits the proliferation of various NHL cell lines in a dose-dependent manner and significantly postpone tumour growth and prolong the survival of xenograft mice model derived from human DLBCL cells. ${ }^{13}$ Additionally, we had conducted a clinical trial on apatinib for relapse or refractory NHL (RR NHL) in our centre. We enrolled 27 patients with RR NHL, including 11 patients with RR DLBCL, accounting for an ORR of $47.6 \%$, suggesting an anti-tumour effect of apatinib to improve the response rate and survival of patients with RR NHL. ${ }^{14}$ Based on preclinical and clinical data, we conducted this open-label, singlearm, prospective trial to further investigate the efficacy and safety of oral administration of apatinib as salvage treatment for patients with RR DLBCL.

\section{Materials and Methods}

\section{Inclusion and Exclusion Criteria}

Patients aged 14-70 years with histological or pathological confirmation of DLBCL were enrolled in this trial (Figure 1). All patients had experienced treatment failure with at least two chemotherapeutic regimens. The patients enrolled were not eligible for ASCT or chimeric antigen receptor $\mathrm{T}$ cells (CART) treatment or had rejected both treatments through their conscious freewill choice without any intentional induction. Other inclusion criteria included

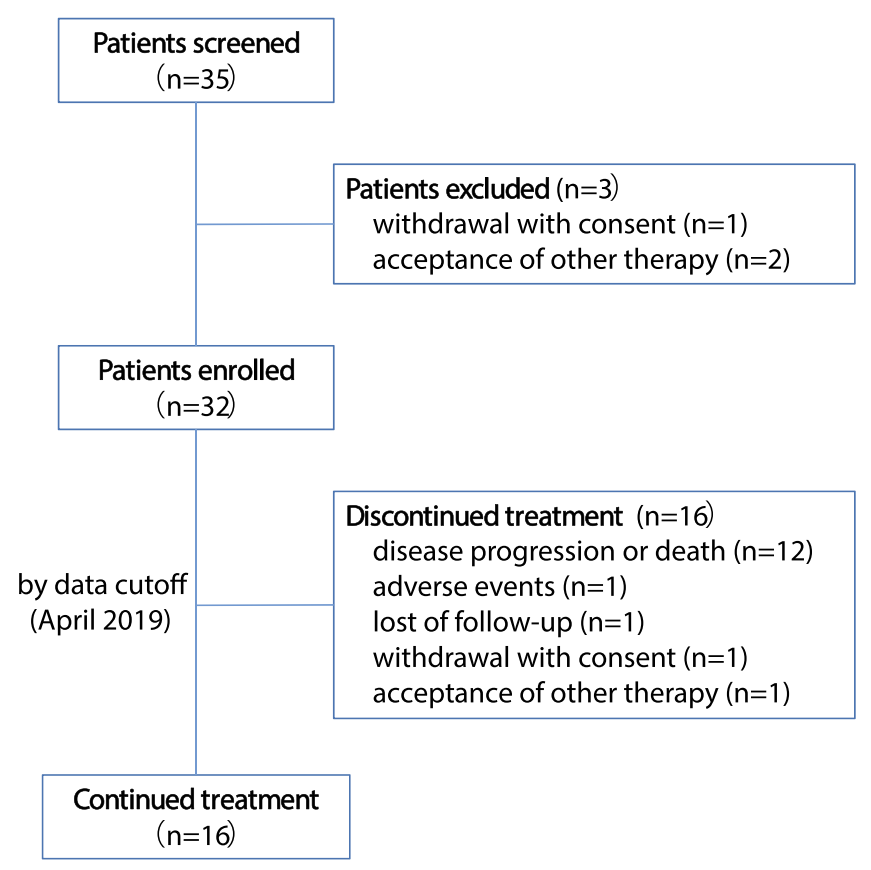

Figure I Trial protocol.

at least one measurable lesion based on the Cheson criteria, ${ }^{15}$ an Eastern Cooperative Oncology Group (ECOG) performance status of $0-2$, adequate haematologic function (absolute neutrophil count $\geq 1.5 \times 10^{9} / \mathrm{L}$, haemoglobin concentration of $\geq 80 \mathrm{~g} / \mathrm{L}$, platelet count $\geq 75 \times$ $10^{9} / \mathrm{L}$ ), hepatic function (total bilirubin $\leq 1.5 \times$ upper limit of normal [ULN], alanine aminotransferase $\leq 2.0 \times \mathrm{ULN}$, aspartate aminotransferase $\leq 2.0 \times \mathrm{ULN}$ ) and renal function (serum creatinine $\leq 1.5 \times \mathrm{ULN}$, creatinine clearance rate $\geq 50 \mathrm{~mL} / \mathrm{mins}$ [Cockcroft-Gault formula]), negative pregnancy test for female patients of reproductive age. Patients with unmanageable hypertension (systolic blood pressure $\geq 140 \mathrm{mmHg} /$ diastolic blood pressure $\geq 90 \mathrm{mmHg}$ and cannot be controlled successfully with drugs), unstable angina or heart failure with cardiac function higher than grade II as defined by the New York Heart Association were excluded. Another key exclusion criterion was gastrointestinal bleeding risk, including active ulcerative lesions with positive occult blood (OB) test result, melena, or hematemesis history within 3 months before this study. An endoscope examination was required for patients with primary gastrointestinal DLBCL with positive OB test result. Patients with any one or more of the following conditions were also excluded: abnormal coagulation function $(\mathrm{INR}>1.5 \times \mathrm{ULN}$, APTT $>1.5 \times \mathrm{ULN}), 24$-hrs urinary total protein (24-hrs UTP) $\geq 1.0 \mathrm{~g}$, central nervous system metastasis, concomitant malignancies, or any severe 
medical problems that may impede the compliance of the trial. (Full inclusion and exclusion criteria are shown in Appendix 1.)

\section{Ethical Clearance}

This trial was performed in accordance with the Good Clinical Practice Guidelines and the Helsinki Declaration and was approved by the ethical committee of the First Affiliated Hospital of Zhengzhou University. All patients were fully informed of the nature and possible AEs caused by apatinib and submitted written informed consent before their participation. For patients younger than 18 years, written informed consent was provided by their parents or legal guardians.

\section{Study Design}

Each enrolled patient was administered apatinib $500 \mathrm{mg}$ once daily as an initial dose. One treatment cycle consists of 28 days, and all patients were continuously administered with the drug half an hour after breakfast daily until disease progression, intolerable toxicities even after three dose reductions, and patient-requested withdrawal. Appropriate supportive care was provided to control AEs. Dose interruptions and reductions were only allowed if grade 3 haematological AEs or grade 2 non-haematological AEs occur. For each treatment cycle, interruptions were allowed for 7 days at maximum continuously or cumulatively, and only two dose reductions is allowed at maximum (from $500 \mathrm{mg}$ daily to $500 \mathrm{mg}$ and $250 \mathrm{mg}$ taken on alternate days, then to $250 \mathrm{mg}$ daily). It should be noted that for intolerable grade 2 toxicities, one dose reduction could also be considered if necessary.

Baseline evaluation before treatment included systemic physical examination, ECOG status assessment, antecedent blood pressure, complete blood counts (CBCs), blood chemistry panel, coagulation function test, routine urinalysis, routine stool test consisting of occult blood (OB), bone marrow evaluation, echocardiography and electrocardiogram, and baseline lesions measured by contrast-enhanced computed tomography (CT) or positron emission tomography (PET). Patients visit the outpatient clinic every cycle to undergo $\mathrm{CBC}$, blood chemistry panel, routine urinalysis, routine stool test measurements, and physical examination. Efficacy was evaluated every 2 months by using contrastenhanced CT. All scans were reviewed by an independent central imaging review group consisting of radiologists and oncologists. AEs were evaluated every cycle according to the National Cancer Institute Common Terminology Criteria for
Adverse Events (version 4.03) and were noted during their monthly outpatient clinic visit or by telephone follow-up.

\section{Assessments}

We considered objective response rate (ORR) as the primary end point, and progression-free survival (PFS), overall survival (OS) plus duration of response (DoR) as the secondary end point. ORR was defined as the ratio of patients who achieved complete response (CR) or partial response (PR) based on the Cheson criteria. ${ }^{15}$ PFS was counted from assignment to documented disease progression or death of any reason, and OS was counted from assignment to death of any reason. For patients without disease progression, PFS and OS were both counted as the time from assignment to the last documented survival assessment. DoR was defined as the interval from the first documented onset of response to disease progression or death. PFS, OS, and DoR were estimated using the Kaplan-Meier method with 95\% CIs.

Considering possible dosage reduction during treatment, the effects of dose reduction on clinical outcomes were evaluated. First, the normality of PFS and OS of the original dose and dose reduction groups was assessed based on the Shapiro-Wilk test. If satisfied, equality of variance would be assessed using the Levene test. Student and Welch t-tests were performed when the equal variance assumption was satisfied and violated, respectively.

Considering the primary end point, ORR, the sample size was initially estimated using Simon's two-stage design with one-sided $\alpha$ error of $5 \%$ and a power of $80 \% .{ }^{16}$ We expected an ORR of at least $40 \%$. The highest objective response of monotherapy in RR DLBCL at that time was $27.5 \%$ by the single-agent lenalidomide. ${ }^{17}$ Taking these factors into account, seven patients were treated at the first stage, and at least two objective responses were required to move on to the second stage. A total sample size of 32 patients should be reached at the second stage of the study. The regimen would be considered successful if $\geq 12$ patients achieved objective responses.

SPSS Statistics software (version 22.0.0; Chicago, IL, USA) and GraphPad Prism software (version 6.07; La Jolla, CA, USA) were used for statistical analysis.

\section{Results \\ Characteristics}

We screened 35 patients and enrolled 32 patients from January 2017 to February 2019. The median age at enrolment was 60 years (range, $25-70$ years), male/female ratio 
was 1.46, and most patients had an ECOG performance status of $0-1$. Three (7.4\%) patients had double/triple hits. Majority of patients had grade III or IV disease and had experienced more than two treatment lines. No patients had prior haematopoietic stem cell transplantation, immunotherapy, or vascular endothelial growth factor (VEGF)/ VEGFR inhibitor treatment. Eighteen (56.3\%) patients had B symptoms. Moreover, 16 (50.0\%) patients had elevated serum lactic dehydrogenase (LDH), and 15 (46.9\%) had elevated serum $\beta 2$ microglobulin. Seven (21.9\%) patients had bone marrow involvement. The baseline characteristics of all patients are listed in Table 1.

\section{Efficacy}

At the data cutoff point (April 2019), 14 (43.8\%) patients achieved ORR, including 2 (6.3\%) CRs and 12 (37.5\%) PRs. Nine (28.1\%) patients showed stable disease (SD), contributing to a disease control rate (DCR) of $71.9 \%$. The median PFS and OS were 6.9 months (95\% CI, 5.8-7.9) and 7.9 months (95\% CI, 7.0-8.7), respectively. For patients with $\mathrm{ABC}$ and $\mathrm{GCB}$ subtypes, no significant difference was found in PFS and OS (6.7 months [95\% CI, 5.4-8.1] vs 6.9 months [95\% CI, 5.7-7.8], 8.0 months [95\% CI, 7.1-9.0] vs 7.8 months [95\% CI, 6.8-8.5]). Two patients achieved CR continued the treatment with the initial dosage and had no disease progression. For those who achieved PR, the median duration of response was 5.0 months (95\% CI 3.5-6.5). For those with objective responses, three patients had late responses observed at 4 months, and all other patients had their responses noted at the first assessment at 2 months. Kaplan-Meier estimates of PFS and OS are shown in Figure 2.

The median duration of follow-up at data analysis time was 8.6 months $(95 \% \mathrm{CI}, 7.3-9.4)$. At the cutoff point, 16 $(50.0 \%)$ patients remained on treatment. Twelve (37.5\%) patients discontinued their treatment because of disease progression or death; one (6.3\%) discontinued because of AEs; and one (3.1\%) had withdrawn consent; one (3.1\%) was lost to follow-up; and one (3.1\%) had accepted other anti-tumour treatments. Twenty-one patients showed tumour shrinkage when compared with their baseline data. The best percentage changes from baseline are shown in Figure 3.

\section{Safety}

No fatal AEs were reported. Generally, the most frequently observed grade 3-4 AEs were hypertension (12.6\%), handfoot syndrome (9.4\%), and leucopenia $(9.4 \%)$, which were
Table I Baseline Characteristics

\begin{tabular}{|c|c|c|}
\hline Characteristics & $\mathbf{N}$ & $\%$ \\
\hline \multicolumn{3}{|l|}{ Gender } \\
\hline Male & 19 & 59.4 \\
\hline Female & 13 & 40.6 \\
\hline \multicolumn{3}{|l|}{ Age } \\
\hline$<60 y$ & 17 & 53.1 \\
\hline$\geq 60 y$ & 15 & 46.9 \\
\hline \multicolumn{3}{|l|}{ ECOG } \\
\hline $0 \sim 1$ & 24 & 75.0 \\
\hline$\geq 2$ & 8 & 25.0 \\
\hline \multicolumn{3}{|l|}{ Serum LDH } \\
\hline Normal & 16 & 50.0 \\
\hline Increased* & 16 & 50.0 \\
\hline \multicolumn{3}{|l|}{ Serum $\beta_{2}$ microglobulin } \\
\hline Normal & 17 & 53.1 \\
\hline Increased* & 15 & 46.9 \\
\hline \multicolumn{3}{|l|}{ B symptoms } \\
\hline Absent & 14 & 43.8 \\
\hline Present & 18 & 56.3 \\
\hline \multicolumn{3}{|l|}{ Bone marrow involvement } \\
\hline Absent & 25 & 78.1 \\
\hline Present & 7 & 21.9 \\
\hline \multicolumn{3}{|l|}{ Ann Arbor clinical stage } \\
\hline I-II & 12 & 37.5 \\
\hline III-IV & 20 & 62.5 \\
\hline \multicolumn{3}{|l|}{$\mathrm{COO}$} \\
\hline$A B C$ & 19 & 59.3 \\
\hline $\mathrm{GCB}$ & 11 & 34.4 \\
\hline NOS & 2 & 6.3 \\
\hline \multicolumn{3}{|l|}{ EBER } \\
\hline Negative & 27 & 84.4 \\
\hline Positive & 5 & 15.6 \\
\hline \multicolumn{3}{|l|}{ Double/triple-hit } \\
\hline Absent & 29 & 90.6 \\
\hline Present & 3 & 7.4 \\
\hline \multicolumn{3}{|l|}{ Previous treatment lines } \\
\hline$=2$ & 11 & 34.4 \\
\hline$>2$ & 21 & 65.6 \\
\hline Baseline of major function & $\mathrm{n}$ & $95 \% \mathrm{Cl}$ \\
\hline $\operatorname{ANC}\left(10^{9} / \mathrm{L}\right)$ & 3.6 & $2.7-4.3$ \\
\hline $\mathrm{HB}(\mathrm{g} / \mathrm{L})$ & 110.4 & $98.1-120.7$ \\
\hline PLT $\left(10^{9} / \mathrm{L}\right)$ & 105.6 & $89.9-127.3$ \\
\hline $\mathrm{TB}(\mu \mathrm{mol} / \mathrm{L})$ & 15.5 & $12.4-18.8$ \\
\hline ALT (U/L) & 35.3 & $32.7-38.8$ \\
\hline AST (U/L) & 34.8 & $29.3-41.5$ \\
\hline
\end{tabular}

(Continued) 
Table I (Continued).

\begin{tabular}{|l|l|l|}
\hline Characteristics & $\mathbf{N}$ & $\%$ \\
\hline $\mathrm{Cr}(\mu \mathrm{mol} / \mathrm{L})$ & 72.2 & $56.1-86.4$ \\
$\mathrm{Ccr}(\mathrm{mL} / \mathrm{mins})$ & 104.4 & $94.6-115.3$ \\
\hline
\end{tabular}

Notes: Double/triple-hit lymphoma refers to lymphoma with rearrangements of MYC and BCL-2 or/and BCL-6, which is also described as high-grade B cell lymphoma (HGBL). Among all of the 32 patients enrolled in this study, two patients lack of EBER results were considered EBER negative, and five patients lack of $B C L$ 2/MYC/BCL-6 FISH results were considered absent of double/triple-hit. *In this study, increased serum LDH level was defined as higher than $245 \mathrm{U} / \mathrm{L}$, and increased Serum $\beta 2$ microglobulin level was defined as higher than $3 \mathrm{mg} / \mathrm{L}$.

Abbreviations: ECOG, Eastern Cooperative Oncology Group; COO, cell of origin; GCB, germinal center B-cell-like; EBER, Epstein-Barr virus-encoded small RNA; ANC, absolute neutrophil count; HB, haemoglobin; PLT, platelet count; LDH, lactic dehydrogenase; TB, total bilirubin; ALT, alanine aminotransferase; AST, aspartate aminotransferase; $\mathrm{Cr}$, creatinine; $\mathrm{Ccr}$, creatinine clearance rate.

also the primary cause of treatment interruptions. The only grade $4 \mathrm{AE}$ recorded was leucopenia (3.1\%). Most common non-haematological grade 3 AEs are hypertension (12.6\%), hand-foot syndrome $(9.4 \%)$, and fatigue $(6.3 \%)$, and the most common haematological grade $3 \mathrm{AE}$ is leucopenia (6.3\%). Of all AEs occurring in at least one patient, hypertension $(62.5 \%)$, proteinuria $(53.1 \%)$, hand-foot syndrome $(40.6 \%)$, and leucopenia $(40.6 \%)$ had the highest frequency. Fatigue (37.5\%) and anorexia (34.3\%) were also frequently observed. Most AEs were of grade 1-2. Notably, coexisting AEs in one patient were not rare. No AE-related deaths were reported. Additionally, no febrile neutropenia or perforation was observed. AEs occurring in at least one patient are shown in Table 2.

The highest blood pressure recorded was 178/100 $\mathrm{mmHg}$, which was observed 8 days after the first dose of apatinib. For this patient, blood pressure was stabilized at normal range 2 days after the administration of thiazide diuretics combined with angiotensin-converting enzyme inhibitor (ACEI), and the patient regained the original dose of apatinib after a 3-day interruption. No hypertensive emergency was observed. A patient with grade 3 anaemia was admitted into the hospital for blood transfusion. Another hospitalized patient, the only patient with grade $4 \mathrm{AE}$, had the lowest white blood cell count (WBC) at $0.9 \times 10^{9} / \mathrm{L}$. This was a senior patient with bone marrow involvement and disease progression. Thus, we were not definite that leucopenia was related to treatment. This patient withdrew from the study and had elevated WBC after administration with granulocyte colony-stimulating factor (GCSF).

\section{Dose Adjustments}

Most dose interruptions were initially observed during the first treatment cycle, with a median of 17 days (interquartile range, 13-22) since entry. Twenty-six (81.2\%) patients experienced temporarily treatment interruption, whereas treatment was continued after an interval of $<7$ days or rational dose adjustments. We noted dose reductions in 17 (53.1\%) patients. Thirteen $(40.6 \%)$ patients had one dose reduction from $500 \mathrm{mg}$ daily to $500 \mathrm{mg}$ and $250 \mathrm{mg}$ on alternate days, and four (12.5\%) had their dose reduced to $250 \mathrm{mg}$ daily. One (3.1\%) patient had permanent treatment interruption due to grade 3 proteinuria. This patient had dose interruption, and 24-hrs UTP was closely monitored after the initial occurrence of grade 3 proteinuria. The

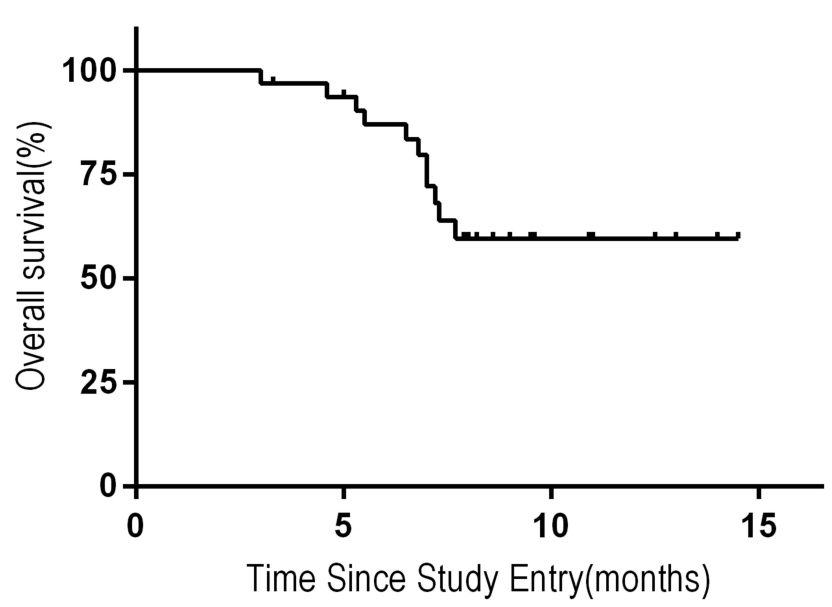

Figure 2 Kaplan-Meier estimates of progression-free survival (PFS) and overall survival (OS). 


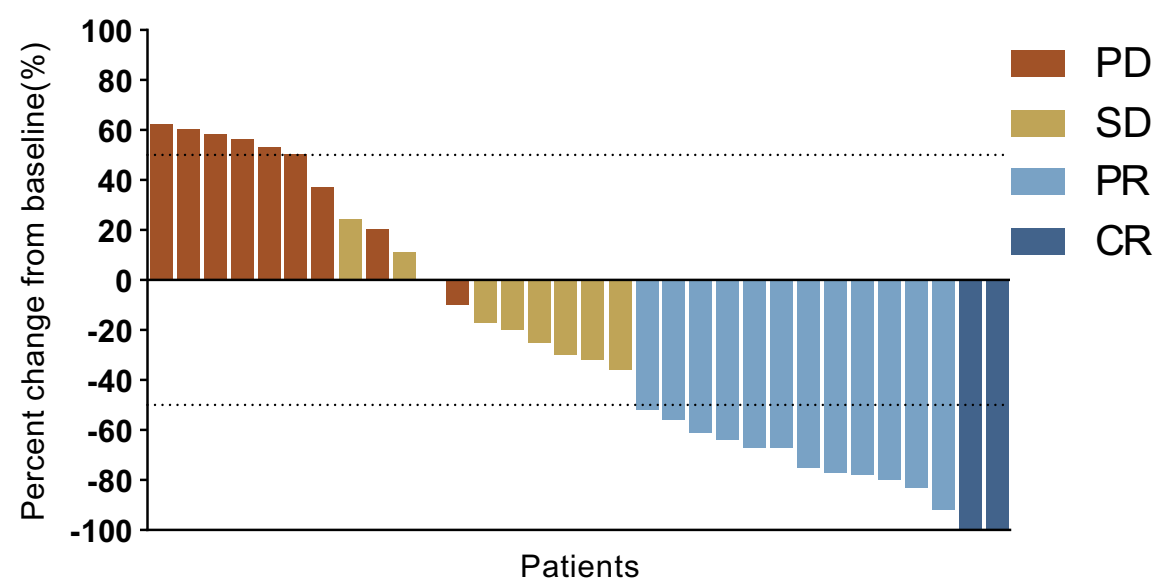

Figure 3 Waterfall plot of best percentage changes from baseline. Waterfall plot of the best percentage changes from baseline of target tumor size is shown for each patient. Dashed line at $-50 \%$ represents the threshold of partial response, and another dashed line at $50 \%$ represents the threshold of progressive disease. One patient had tumor shrinkage despite of progressive disease. One patient had no tumor size change from baseline.

original dose was regained after 24-hrs UTP $<2.0 \mathrm{~g}$, and one dose reduction was applied after the second occurrence of grade 3 proteinuria. The patient had permanent dose interruption after the recurrence of grade 3 proteinuria with second dose reduction, and no disease progression was recorded before withdrawal. Dose adjustments and first dose interruption noted since entry are listed in Table 3.

Welch $t$-test was used to compare the PFS and OS between patients with or without dose reduction (53.1\% vs $46.9 \%$ ). With $\mathrm{P}<0.05$ as threshold, comparison of both PFS and OS between two groups showed no statistical significance (Table 4).

\section{Discussion}

This is the first study to report the efficacy and safety profile of apatinib for RR DLBCL. As the first oral antiangiogenesis drug for advanced tumours, apatinib was approved by the China Food and Drug administration for patients with advanced gastric cancer; however, previous studies mainly focused on solid tumours. ${ }^{8-11}$ The role of angiogenesis in lymphoma has been long confirmed, and increased expression of VEGF and its receptors (VEGFR) has been proven to be related with DLBCL progression. ${ }^{17}$ Apatinib has therapeutic potential for DLBCL by blocking the intracellular adenosine triphosphate-binding site of VEGFR-2, inhibiting VEGFR-2 autophosphorylation and downstream Ras/Raf/MEK/ERK and PI3K pathway activation, thereby interfering with tumourigenesis and progression. ${ }^{13,18}$ Wang et al reported the anti-tumour activity of apatinib in DLBCL (both GCB and ABC subtypes) in a preclinical setting. ${ }^{13}$ Apatinib showed cytotoxicity and induced apoptosis in DLBCL cell lines (OCI-ly1, OCI-ly3, SU-DHL-2, and SU-DHL-4), and significantly suppressed tumour progression and prolonged survival in a xenograft mouse model without obvious bodyweight loss, indicating the efficacy and tolerability of apatinib. This study also showed that apatinib down-regulated several Ras pathway targets and had a kinase inhibitory effect on c-Src, c-Kit, and PDGFRb besides VEGFR-2, which may also contribute to cytotoxicity in vitro and anti-angiogenesis in vivo of apatinib in DLBCL.

The current options for RR DLBCL are limited. AntiPD-1 monoclonal antibodies, BTK inhibitors, anti-CD79b antibody-drug conjugate, PI3K inhibitor, BCL-2 inhibitors, CD20-targeted monoclonal antibodies, immunomodulators, and CAR-T therapies have been investigated as treatment for RR DLBCL. ${ }^{19-24}$ Appendix 2 shows the comparison between representative agents and apatinib. In this study, an objective response was observed in 43.8\% of patients (median PFS, 6.9 months; 95\% CI, 5.8-7.9; median OS, 7.9 months; 95\% CI, 7.0-8.7). Besides, nine SD patients contributed to a DCR of $71.9 \%$. In terms of efficacy, apatinib was slightly superior than ibrutinib and obinutuzumab in monotherapy, ${ }^{20,22}$ and was obviously superior than nivolumab, venetoclax, and lenalidomide. ${ }^{19,21,23}$ The PI3K inhibitor copanlisib had an ORR of $37.5 \%$ and $13.6 \%$ in $\mathrm{ABC}$ and GCB patients, respectively, ${ }^{25}$ showing a slightly lower ORR compared with apatinib. However, apatinib was inferior compared with polatuzumab-vedotin, an anti-CD79b antibody-drug conjugate combined with monomethyl auristatin $\mathrm{E}$, and the 
Table 2 Treatment-Related Adverse Events Occurred in More Than One Patient

\begin{tabular}{|c|c|c|c|c|}
\hline Adverse Events & All (\%) & $\begin{array}{l}\text { Grade } \\
\text { I-2 (\%) }\end{array}$ & $\begin{array}{l}\text { Grade } \\
3(\%)\end{array}$ & $\begin{array}{l}\text { Grade } \\
4(\%)\end{array}$ \\
\hline $\begin{array}{l}\text { General status } \\
\text { Fatigue }\end{array}$ & $12(37.5)$ & $10(3 \mid .2)$ & $2(6.3)$ & 0 \\
\hline $\begin{array}{l}\text { Hematological system } \\
\text { Leukopenia } \\
\text { Neutropenia } \\
\text { Anemia } \\
\text { Thrombocytopenia }\end{array}$ & $\begin{array}{l}13(40.6) \\
10(31.2) \\
7(21.8) \\
5(15.6)\end{array}$ & $\begin{array}{l}10(31.2) \\
9(28.1) \\
5(15.6) \\
4(12.5)\end{array}$ & $\begin{array}{l}2(6.3) \\
\text { I }(3.1) \\
\text { I }(3.1) \\
\text { I }(3.1)\end{array}$ & $\begin{array}{l}1(3.1) \\
0 \\
0 \\
0\end{array}$ \\
\hline $\begin{array}{l}\text { Cardiovascular system } \\
\text { Hypertension }\end{array}$ & $20(62.5)$ & $16(50.0)$ & $4(12.5)$ & 0 \\
\hline $\begin{array}{l}\text { Skin and subcutaneous } \\
\text { tissue } \\
\text { Hand-foot syndrome } \\
\text { Mucositis }\end{array}$ & $\begin{array}{l}13(40.6) \\
3(9.4)\end{array}$ & $\begin{array}{l}10(31.2) \\
3(9.4)\end{array}$ & $\begin{array}{l}3(9.4) \\
0\end{array}$ & $\begin{array}{l}0 \\
0\end{array}$ \\
\hline $\begin{array}{l}\text { Gastrointestinal } \\
\text { system } \\
\text { Abdominal pain } \\
\text { Diarrhea } \\
\text { Anorexia } \\
\text { Fecal occult blood } \\
\text { Nausea }\end{array}$ & $\begin{array}{l}3(9.4) \\
4(12.5) \\
11(34.3) \\
4(12.5) \\
5(15.6)\end{array}$ & $\begin{array}{l}3(9.4) \\
4(12.5) \\
10(31.2) \\
3(9.4) \\
5(15.6)\end{array}$ & $\begin{array}{l}0 \\
0 \\
I(3.1) \\
I(3.1) \\
0\end{array}$ & $\begin{array}{l}0 \\
0 \\
0 \\
0 \\
0\end{array}$ \\
\hline $\begin{array}{l}\text { Urinary system } \\
\text { Proteinuria }\end{array}$ & $17(53.1)$ & $16(50.0)$ & I (3.1) & 0 \\
\hline $\begin{array}{l}\text { Blood biochemistry } \\
\text { AST/ALT increase } \\
\text { Bilirubin increase } \\
\text { Hypoproteinemia }\end{array}$ & $\begin{array}{l}7(21.8) \\
5(15.6) \\
3(9.4)\end{array}$ & $\begin{array}{l}6(18.7) \\
4(12.5) \\
3(9.4)\end{array}$ & $\begin{array}{l}\text { I (3.I) } \\
\text { I (3.1) } \\
0\end{array}$ & $\begin{array}{l}0 \\
0 \\
0\end{array}$ \\
\hline $\begin{array}{l}\text { Mental and nervous } \\
\text { system } \\
\text { Headache }\end{array}$ & $3(9.4)$ & $3(9.4)$ & 0 & 0 \\
\hline
\end{tabular}

single-agent ORR was $56 \% .^{26}$ Although comparisons between different trials can be difficult, we assume that apatinib excels several agents in efficacy profile and has the advantage of easy access and economic effectiveness. Additionally, oral administration without infusion pump may prevent hospitalization for patients.

The most frequently observed AEs in our study were hypertension, proteinuria, hand-foot syndrome, and leucopenia, which were consistent with previous studies on solid tumours, ${ }^{8,27,28}$ but with a higher rate of haematological AEs, which may due to latent-impaired bone marrow reservation resulting from previous intensive chemotherapy. Hypertension (62.5\%), proteinuria (53.1\%), and hand-foot syndrome $(40.6 \%)$ were the most frequently
Table 3 Dose Adjustments and First Dose Interruption Since Entry

\begin{tabular}{|c|c|}
\hline Dose & $\begin{array}{l}\text { n (\%) or Time } \\
\text { (days) }\end{array}$ \\
\hline Dose Adjustments & \\
\hline No dose adjustments $(500 \mathrm{mg})$ & 15 (46.9) \\
\hline $\begin{array}{l}\text { Dose level - I (500 mg and } 250 \mathrm{mg} \text { on } \\
\text { alternate days) }\end{array}$ & $13(40.6)$ \\
\hline Dose level -2 (250 mg) & $4(12.5)$ \\
\hline Dose interrupted temporarily & $26(8 I .2)$ \\
\hline Dose interrupted permanently & $I(3.1)$ \\
\hline $\begin{array}{l}\text { First dose interruption since entry(days) } \\
\text { Median (IQR) }\end{array}$ & $17(13,22)$ \\
\hline
\end{tabular}

Table 4 Comparison Between No Dose Reduction Group and Dose Reduction Group

\begin{tabular}{|l|l|l|l|l|l|}
\hline Outcome & \multicolumn{2}{l|}{$\begin{array}{l}\text { No Dose } \\
\text { Reduction } \\
(\mathbf{n}=15)\end{array}$} & $\begin{array}{l}\text { Dose } \\
\text { Reduction } \\
(\mathbf{n}=\mathbf{1 7})\end{array}$ & \multirow{2}{*}{ P value (2-Tailed) } \\
\cline { 2 - 5 } & Mean & SD & Mean & SD & \\
\hline PFS $(\mathrm{m})$ & 6.8 & 2.6 & 6.9 & 2.8 & $>0.05$ \\
OS $(\mathrm{m})$ & 7.8 & 2.7 & 8.0 & 3.0 & $>0.05$ \\
\hline
\end{tabular}

observed non-haematological AEs, which were also considered as features of antiangiogenics. Most patients with the abovementioned AEs were of grade 1-2. Thiazide diuretics, calcium antagonists, ACEIs, or angiotensin receptor blockers (ARBs) were used in hypertensive patients as single agent or combination. Patients who showed consecutive $(++)$ proteinuria underwent $24 \mathrm{hrs}$ UTP and consulted with nephrologists for treatment assistance. Intensive skincare was provided to those with handfoot syndrome, and moisturizer containing urea or corticosteroids was added as necessary. Leucopenia was the most common grade 3-4 haematological AE in this study and was treated by GCSF if necessary. Generally, all AEs improved after treatment interruption for $<7$ days and appropriate supportive care. Most of the AEs were initially observed during the first 3 weeks, implying the necessity of close monitoring and follow-up within this timeframe.

Interestingly, early occurrence of apatinib-related AEs was reported to be predictive biomarkers for treatment efficacy. ${ }^{29}$ Patients with anorexia and grade 2 or worse fatigue and hand-foot syndrome tended to acquire prolonged PFS. ${ }^{9}$ Apatinib-related hypertension was also 
reported to be a valid biomarker for preferable anti-tumour efficacy. ${ }^{30,31}$ Here, the patient with the highest blood pressure also had the longest PFS. Besides, although many patients required dose modifications or interruptions during treatment due to AEs, most of them resumed therapeutic dosage and continued the treatment, and the clinical outcome between patients with original dose and those with dose reduction was not statistically significant, suggesting that appropriate dose reduction did not necessarily lead to inferior clinical outcome.

Some studies of apatinib on solid tumours started with a higher initial dose of $750 \mathrm{mg}^{11}$ or $850 \mathrm{mg} ;{ }^{8}$ however, frequent dose modifications and serious adverse events (SAEs) were observed. According to $\mathrm{Xu}$ et $\mathrm{al}^{11}$ starting apatinib with a dose of $750 \mathrm{mg}$ resulted in dose delay with at least one cycle and dose reduction in $84.0 \%$ of patients, and SAEs in $12 \%$ patients with two possibly drug-related deaths. Additionally, the OS of the 750- and 500-mg groups were 8.3 and 10.6 months, respectively. Considering above factors and the relatively advanced age profile and ECOG status of patients with RR DLBCL in our centre, $500 \mathrm{mg}$ daily was continued as the initial apatinib dose. Nevertheless, some modifications were made based on our previous study on apatinib for NHL, such as making 3 weeks as one treatment cycle with an interval of $<1$ week continuously or cumulatively. ${ }^{14}$ In the present study, we prolonged our treatment cycle to 4 weeks, and an interval $\leq 7$ days was also allowed for each cycle. The PFS of this study was slightly shorter than that previously (6.9 months [95\% CI, 5.8-7.9] vs 7.1 months [95\% CI, 4.2-7.3]); however, the OS was better (7.9 months [95\% CI, 7.0-8.7] vs 7.3 months [95\% CI, 7.17.9]). ORR of this study is slightly lower $(43.8 \%$ vs $47.6 \%$ ), and this may be due to the fact that only 11 out of 27 patients were DLBCL in the previous study. Besides, our previous report did not include dose modification profile and relative clinical outcomes. In the present study, although $53.1 \%$ of all patients experienced dose reduction, the clinical outcome was not inferior for these patients compared with those who did not experience dose reductions, and approximately all these patients continued treatment after proper intervention or short interval. Indeed, the proportion of patients who experienced dose interruptions was higher than expected, but approximately all of them regained the dosage afterwards. We also found out that there was no statistical significance between patients with ABC and GCB subtype. This result accords with the findings of a preclinical study that apatinib exhibited similar anti-tumour activity in both DLBCL subtypes. ${ }^{13}$ These results provided valuable experience for other investigators to determine their preferable initial dose and treatment cycle.

Considering the efficacy and safety profile of apatinib, it may be of additional therapeutic potential to combine apatinib with chemotherapy for RR DLBCL treatment. By promoting vascular normalization in tumour microenvironment and enhancing drug delivery and permeating, ${ }^{32,33}$ antiangiogenics combining chemotherapy has been proven effective in multiple tumours. ${ }^{34,35}$ In the AEROC study, apatinib combined with etoposide achieved an ORR of $54 \%$ with tolerable AEs for platinum-resistant or platinumrefractory ovarian cancer. ${ }^{9}$ Although from the MAIN study, bevacizumab added to R-CHOP did not prolong PFS as expected; ${ }^{36}$ thus, results may due to cardiac toxicity and discontinuation of intravenous bevacizumab, ${ }^{37}$ whereas apatinib has the advantage of administration continuity. Additionally, apatinib has been reported to reverse ABCB1- and ABCG2-mediated multiple drug resistance inhibition in a concentration-dependent manner. ${ }^{38}$ Based on the present study, further investigations on apatinib combined with DHAP (dexamethasone, cytarabine, and cisplatin) as salvage treatment for RR DLBCL are ongoing in our centre.

With the potential superiority of home administration without frequent hospitalization, apatinib can be used for patients with RR DLBCL, considering its favourable efficacy, manageable AEs, improved patient adherence, and economic effectiveness. Combination with chemotherapy or other targeted drugs, including anti-angiogenesis agents with different mechanisms, ${ }^{39}$ may be promising strategies to improve the anti-tumour effects of apatinib and reverse drug resistance.

Nevertheless, this study has limitations. Because it was single arm without a control group, the comparisons between apatinib and placebo in the same centre was not performed. However, several similar studies on other agents in RR DLBCL had provided sufficient data for comparison with respect to efficacy and safety.

\section{Conclusion}

Our study showed that home administration of apatinib has promising efficacy and tolerable AEs in patients with RR DLBCL. Further investigations of Phase III trials and combination therapy of apatinib with chemotherapy are warranted. 


\section{Data Sharing Statement}

All patient data collected during the trial will be shared after deidentification. Other study-related documents, including the study protocol, data analysis plan, informed consent form, and analytic code will be made available. Proposals for data access should be directed to xinranma2000@hotmail.com. Once approved, the data will be sent through email. The data will be made available from 3 to 36 months following article publication.

\section{Acknowledgments}

This study was supported by the National Natural Science Foundation of China (No. 81570203).

\section{Disclosure}

The authors report no conflicts of interest in this work.

\section{References}

1. Coiffier B. Diffuse large cell lymphoma. Curr Opin Oncol. 2001;13:325-334. doi:10.1097/00001622-200109000-00003

2. Coiffier B, Thieblemont C, Van Den Neste E, et al. Long-term outcome of patients in the LNH-98.5 trial, the first randomized study comparing rituximab-CHOP to standard $\mathrm{CHOP}$ chemotherapy in DLBCL patients: a study by the groupe d'Etudes des lymphomes de 1'Adulte. Blood. 2010;116:2040-2045. doi:10.1182/blood-201003-276246

3. Sarkozy C, Sehn LH. Management of relapsed/refractory DLBCL. Best Pract Res Clin Haematol. 2018;31:209-216. doi:10.1016/j. beha.2018.07.014

4. Hunter BD, Herr M, Meacham PJ, et al. Late relapses after high-dose chemotherapy and autologous stem cell transplantation in patients with diffuse large B-cell lymphoma in the rituximab era. Clin Lymphoma Myeloma Leuk. 2017;17:145-151. doi:10.1016/j.clml. 2016.11.001

5. Tilly H, Gomes da Silva M, Vitolo U, et al. Diffuse large b-cell lymphoma (DLBCL): ESMO clinical practice guidelines for diagnosis, treatment and follow-up. Ann Oncol. 2015;26(Suppl 5):v116v125. doi:10.1093/annonc/mdv304

6. Jorgensen JM, Sorensen FB, Bendix K, et al. Angiogenesis in nonHodgkin's lymphoma: clinico-pathological correlations and prognostic significance in specific subtypes. Leuk Lymphoma. 2007; 48:584-595. doi:10.1080/10428190601083241

7. Mangi MH, Newland AC. Angiogenesis and angiogenic mediators in haematological malignancies. Br J Haematol. 2000;111:43-51. doi:10.1046/j.1365-2141.2000.02104.x

8. Li J, Qin S, Xu J, et al. Randomized, double-blind, placebo-controlled phase III trial of apatinib in patients with chemotherapy-refractory advanced or metastatic adenocarcinoma of the stomach or gastroesophageal junction. $J$ Clin Oncol. 2016;34:1448-1454. doi:10.1200/JCO.2015.63.5995

9. Lan CY, Wang Y, Xiong Y, et al. Apatinib combined with oral etoposide in patients with platinum-resistant or platinum-refractory ovarian cancer (AEROC): a Phase 2, single-arm, prospective study. Lancet Oncol. 2018;19:1239-1246. doi:10.1016/S1470-2045(18)30349-8

10. Li F, Zhu T, Cao B, Wang J, Liang L. Apatinib enhances antitumour activity of EGFR-TKIs in non-small cell lung cancer with EGFR-TKI resistance. Eur J Cancer. 2017;84:184-192. doi:10.1016/j.ejca.20 17.07 .037
11. Hu X, Zhang J, Xu B, et al. Multicenter Phase II study of apatinib, a novel VEGFR inhibitor in heavily pretreated patients with metastatic triple-negative breast cancer. Int $J$ Cancer. 2014;135: 1961-1969. doi:10.1002/ijc.28829

12. Zheng K, Xu M, Wang L, Yu X. Efficacy and safety of apatinib in advance osteosarcoma with pulmonary metastases: a single-center observational study. Medicine (Baltimore). 2018;97:e11734. doi:10.1097/MD.0000000000011734

13. Wang Y, Deng M, Chen Q, et al. Apatinib exerts anti-tumor activity to non-Hodgkin lymphoma by inhibition of the Ras pathway. Eur J Pharmacol. 2019;843:145-153. doi:10.1016/j. ejphar.2018.11.012

14. Li L, Xiao S, Zhang L, et al. An open label, single-armed, exploratory study of apatinib (a novel VEGFR-2 tyrosine kinase inhibitor) in patients with relapsed or refractory non-Hodgkin lymphoma. Oncotarget. 2018;9:16213-16219. doi:10.18632/oncotarget.23806

15. Cheson BD, Pfistner B, Juweid ME, et al. Revised response criteria for malignant lymphoma. J Clin Oncol. 2007;25:579-586. doi:10.1200/JCO.2006.09.2403

16. Simon R. Optimal two-stage designs for phase II clinical trials. Control Clin Trials. 1989;10:1-10. doi:10.1016/0197-2456(89)90 015-9

17. Ramakrishnan V, Timm M, Haug JL, et al. Sorafenib, a multikinase inhibitor, is effective in vitro against non-Hodgkin lymphoma and synergizes with the mTOR inhibitor rapamycin. Am J Hematol. 2012;87:277-283. doi:10.1002/ajh.22263

18. Olsson AK, Dimberg A, Kreuger J, Claesson-Welsh L. VEGF receptor signalling - in control of vascular function. Nat Rev Mol Cell Biol. 2006;7:359-371.

19. Ansell SM, Minnema MC, Johnson P, et al. Nivolumab for relapsed/ refractory diffuse large B-cell lymphoma in patients ineligible for or having failed autologous transplantation: a single-arm, phase II study. $J$ Clin Oncol. 2019;37:481-489. doi:10.1200/JCO.18.00766

20. Wilson WH, Young RM, Schmitz R, et al. Targeting b cell receptor signaling with ibrutinib in diffuse large B cell lymphoma. Nat Med. 2015;21:922-926. doi:10.1038/nm.3884

21. Davids MS, Roberts AW, Seymour JF, et al. Phase I first-in-human study of venetoclax in patients with relapsed or refractory non-Hodgkin lymphoma. J Clin Oncol. 2017;35:826-833. doi:10. 1200/JCO.2016.70.4320

22. Morschhauser FA, Cartron G, Thieblemont C, et al. Obinutuzumab (GA101) monotherapy in relapsed/refractory diffuse large B-cell lymphoma or mantle-cell lymphoma: results from the phase II GAUGUIN study. J Clin Oncol. 2013;31:2912-2919. doi:10.1200/ JCO.2012.46.9585

23. Czuczman MS, Trneny M, Davies A, et al. A phase $2 / 3$ multicenter, randomized, open-label study to compare the efficacy and safety of lenalidomide versus investigator's choice in patients with relapsed or refractory diffuse large B-cell lymphoma. Clin Cancer Res. 2017;23:4127-4137. doi:10.1158/1078-0432.CCR-16-2818

24. Neelapu SS, Locke FL, Bartlett NL, et al. Axicabtagene ciloleucel CAR T-cell therapy in refractory large B-cell lymphoma. $N$ Engl J Med. 2017;377:2531-2544. doi:10.1056/NEJMoa1707447

25. Lenz G, Hawkes E, Verhoef G, et al. Phase II study of single-agent copanlisib in patients with relapsed or refractory diffuse large B-cell lymphoma (DLBCL). J Clin Oncol. 2017;35:7536. doi:10.1200/ JCO.2017.35.15_suppl.7536

26. Palanca-Wessels MC, Czuczman M, Salles G, et al. Safety and activity of the anti-CD79b antibody-drug conjugate polatuzumab vedotin in relapsed or refractory B-cell non-Hodgkin lymphoma and chronic lymphocytic leukaemia: a Phase 1 study. Lancet Oncol. 2015;16:704-715. doi:10.1016/S1470-2045(15)70128-2

27. Liu Z, Ou W, Li N, Wang SY. Apatinib monotherapy for advanced non-small cell lung cancer after the failure of chemotherapy or other targeted therapy. Thorac Cancer. 2018;9:1285-1290. doi:10.1111/ 1759-7714.12836 
28. Fang SC, Zhang HT, Zhang YM, Xie WP. Apatinib as post second-line therapy in EGFR wild-type and ALK-negative advanced lung adenocarcinoma. Onco Targets Ther. 2017;10:447-452. doi:10. 2147/OTT.S126613

29. Liu X, Qin S, Wang Z, et al. Early presence of anti-angiogenesisrelated adverse events as a potential biomarker of antitumor efficacy in metastatic gastric cancer patients treated with apatinib: a cohort study. J Hematol Oncol. 2017;10:153. doi:10.1186/s13045-0170521-0

30. Fang SC, Huang W, Zhang YM, Zhang HT, Xie WP. Hypertension as a predictive biomarker in patients with advanced non-small-cell lung cancer treated with apatinib. Onco Targets Ther. 2019;12:985-992. doi:10.2147/OTT.S189984

31. Wu D, Liang L, Nie L, et al. Efficacy, safety and predictive indicators of apatinib after multilines treatment in advanced nonsquamous nonsmall cell lung cancer: apatinib treatment in nonsquamous NSCLC. Asia Pac J Clin Oncol. 2018;14:446-452. doi:10.1111/ajco.12870

32. Park JS, Kim IK, Han S, et al. Normalization of tumor vessels by Tie2 activation and Ang2 inhibition enhances drug delivery and produces a favorable tumor microenvironment. Cancer Cell. 2017;31:157-158. doi:10.1016/j.ccell.2016.12.009

33. Fukumura D, Kloepper J, Amoozgar Z, Duda DG, Jain RK. Enhancing cancer immunotherapy using antiangiogenics: opportunities and challenges. Nat Rev Clin Oncol. 2018;15:325-340. doi:10.1038/nrclinonc.2018.29
34. Hu W, Fang J, Nie J, et al. Efficacy and safety of extended use of platinum-based doublet chemotherapy plus endostatin in patients with advanced nonsmall cell lung cancer. Medicine (Baltimore). 2016;95:e4183. doi:10.1097/MD.0000000000004183

35. Reck M, Kaiser R, Mellemgaard A, et al. Docetaxel plus nintedanib versus docetaxel plus placebo in patients with previously treated non-small-cell lung cancer (LUME-Lung 1): a Phase 3, double-blind, randomised controlled trial. Lancet Oncol. 2014;15:143-155. doi:10.1016/S1470-2045(13)70586-2

36. Seymour JF, Pfreundschuh M, Trneny M, et al. R-CHOP with or without bevacizumab in patients with previously untreated diffuse large b-cell lymphoma: final main study outcomes. Haematologica. 2014;99:1343-1349. doi:10.3324/haematol.2013.100818

37. La Vine DB, Coleman TA, Davis CH, Carbonell CE, Davis WB. Frequent dose interruptions are required for patients receiving oral kinase inhibitor therapy for advanced renal cell carcinoma. Am J Clin Oncol. 2010;33:217-220. doi:10.1097/COC.0b013e3181a650a6

38. Mi YJ, Liang YJ, Huang HB, et al. Apatinib (YN968D1) reverses multidrug resistance by inhibiting the efflux function of multiple ATP-binding cassette transporters. Cancer Res. 2010;70:7981-7991. doi:10.1158/0008-5472.CAN-10-0111

39. Kerbel RS. Therapeutic implications of intrinsic or induced angiogenic growth factor redundancy in tumors revealed. Cancer Cell. 2005;8:269-271. doi:10.1016/j.ccr.2005.09.016

\section{Publish your work in this journal}

Drug Design, Development and Therapy is an international, peerreviewed open-access journal that spans the spectrum of drug design and development through to clinical applications. Clinical outcomes, patient safety, and programs for the development and effective, safe, and sustained use of medicines are a feature of the journal, which has also been accepted for indexing on PubMed Central. The manuscript management system is completely online and includes a very quick and fair peer-review system, which is all easy to use. Visit http://www. dovepress.com/testimonials.php to read real quotes from published authors. 